\title{
The Exploration of Capacitive Effects of XLPE Cables in Medium Voltage Distribution Systems
}

\author{
Salih Bilgiç $^{1}\left(\mathbb{D}\right.$, Cemile Bardak $^{1^{*}(\mathrm{C})}$ \\ ${ }^{1}$ Department of Electrical and Electronics Engineering, Manisa Celal Bayar University, Manisa, Turkey
}

Geliş / Received: 07/06/2021, Kabul / Accepted: 28/08/2021

\begin{abstract}
Cross-linked polyethylene insulation (XLPE) type underground power cables used in medium and low voltage distribution systems bring out a reactive effect with capacitive character due to the constructional properties of XLPE cables. If this effect is not eliminated, it causes negative influences on losses, cost, and capacity. Therefore, this study focused on the capacitive effects of XLPE type underground cables and the appropriate compensation systems to overcome the issue on a medium voltage distribution system with $5500 \mathrm{~m}-\mathrm{length}$. The measurements taken from a medium voltage substation were compared to corresponding simulation results. As a result, a very successful match between simulation and measurements was achieved. Furthermore, a series of suggestions for establishing appropriate compensation was presented, which were expected to serve the more efficient transmission and distribution of energy. Since the need for more energy and the amount of utilization have been increasing, it is compulsory to carry out the works to decrease the loss rate of the transmission and distribution of energy.
\end{abstract}

Keywords: XLPE type cables, compensation, capacitive effect, shunt reactor, MV distribution network

XLPE Kabloların Orta Gerilim Dağıtım Sistemlerinde Kapasitif Etkisinin İncelenmesi

Öz

Orta ve alçak gerilim dağıtım sistemlerinde kullanılan çapraz bağlı polietilen yalıtım (XLPE) tipi yeraltı güç kabloları, yapısal özellikleri nedeniyle kapasitif karakterli reaktif bir etki oluştururlar. Bu etki ortadan kaldırılamazsa, kayıplar, maliyetler, ve kapasite üzerinde olumsuz etki oluşturur. Bu nedenle, bu çalışma 5500 m uzunluğunda bir orta gerilim dağıtım sistemindeki XLPE tipi yeraltı kablolarının kapasitif etkilerine ve bu etkilerin üstesinden gelebilmek için uygun kompanzasyon sistemlerine odaklanmaktadır. Orta gerilim trafo merkezinden alınan ölçümler, simülasyon sonuçlarıyla karşılaştırılmıştır. Sonuç olarak, simülasyon ve ölçümler arasında çok başarılı bir eşleşme sağlanmıştır. Ayrıca, daha verimli enerji iletimi ve dağıtımına hizmet etmesi beklenen uygun kompanzasyonun oluşturulmasına yönelik bir dizi öneri sunulmaktadır. Daha fazla enerji ihtiyacı ve kullanım miktarı arttığı için enerjinin iletim ve dağıtımındaki kayıp oranını azaltacak çalışmaların yapılması gereklidir.

Anahtar Kelimeler: XLPE kablo, kompanzasyon, kapasitif etki, şönt reaktör, orta gerilim dağıtım şebekesi

*Corresponding Author: cemile.bardak@cbu.edu.tr 


\section{Introduction}

Electrical energy is most preferred when compared with other forms of energy because of its technical and economic advantages in the fields of production, distribution, transmission, and end-usage. Moreover, the electricity should be used with the highest efficiency in the existing energy production to meet the increasing energy demand besides increasing generation (Ahmad \& Zhang, 2020). Generally, the distribution and transmission of energy in residential centers are provided through underground cables. Although facility costs of XLPE cables are more expensive than overhead lines, it is safer in terms of life and property safety in residential areas. In addition, it has a longer life than overhead lines, high-grade resistance against chemical factors, and ambient conditions (Thomas et al., 2016).

Electrical plants can be established according to the characteristics of the installation area. However, since they cannot be situated in areas close to the end-users, they are usually installed away from consumption points. Some of the reasons for this may include access to raw materials, environmental factors, transmission, and distribution difficulties. The best example of this is experienced in Turkey ("Turkish Electricity Transmission Corporation," n.d.). While most of the industry and population settlements are in western regions, power plants that meet the power needs due to their geographical location and natural features are in the eastern areas of the country. As a result, this energy must be transported to cities in the western regions, where energy consumption is high, with long transmission and distribution lines. Therefore, it is seen how essential the transmission and distribution of electrical energy is for Turkey. The produced electrical energy is transmitted in both active and reactive current forms to the enduser. The reactive current affects all transmission and distribution system elements by causing losses and imposes a load on the system while not providing any positive contribution to the operation. Thus, the elimination of the reactive current formed in the network automatically increases the capacity of transformers. Furthermore, the switches and fuses with a protection element are not required to be chosen large, and the cable sections can be shrunk. As a result, investment costs decrease, and more electrical energy can be delivered to users through the same operating system. Besides, the reactive energy consumption will be within limits allowed by the distribution regulations, and the users are most likely to pay less for electricity consumption.

Reducing reactive power is known as compensation; however, it brings some disadvantages, especially the emergence of harmonics. Compensation on the low voltage side is not enough to get the power factor to the desired level to eliminate the unfavorable effects of reactive power. It is also significant to eliminate the impact of reactive power in Medium Voltage (MV) networks due to the capacitive effect created by XLPE cables (Janning \& Bocquel, 2005; Zhang et al., 2008)

In 2017, the DC voltage cables were operated with modular multilevel converters, and network capacity and efficiency increase were investigated. As a result, the effects of XLPE refurbishment cables designed to work under DC conditions for AC were discussed using the imposed electric fields, thermal profile, and service life (Shekhar et al., 2017). Furthermore, in a study, an intuitive approach was proposed that allowed the automatic creation of multiple connection circuits and the calculation of the inductive effects caused by the connection of the sheaths and the distance between the cables, taking into account the stimulating effects in the modeling of high voltage underground cables (Santos \& Calafat, 2019). In another study with XLPE cables, a modified 2D model was created to model the thermal field distribution of the $320 \mathrm{kV}$ DC cable, and based on this, the electric field distribution in the XLPE insulation was examined by the finite element method regardless of the field charge effect (Liu et al., 2018). 
A quantitative analysis method has been developed for the inductive effect of the cross-linked High Voltage (HV) cable lines applied on the peripheral metal installations on the power transmission capacity. The main problem is that most of the surrounding metal installations are located on the surface and cannot be visually identified or verified (Popović, 2020). In another study conducted in this area, evaluations were made to optimize spatial power allocation in HVDC-related wind power plants. In general, it is known that the optimized reactive power position can reduce component load and power losses. In addition to improving the voltage profile with the proposed method, it has effectively reduced losses compared to traditional reactive power distribution strategies (Schönleber et al., 2017).

There are also studies on XLPE cables to eliminate the unfavorable effects caused by partial discharges and water trees (Peter Werelius et al., 1998) (Yu et al., 2019). A capacitive connection electrode can be used between the protective layer and an additional aluminum foil to measure partial discharge (PD) in long-distance lines (Ra et al., 2019). Polymerically insulated power cables are used widely for power transmission and distribution in electrical systems. Comprehensive high voltage and quality control tests are performed for the performance evaluation of the line. During the investigations, the cable ends must be prepared carefully to terminate appropriately (Malik et al., 2014). Another study is on the steady-state and transient behavior analysis of underground cables in $380 \mathrm{kV}$ transmission networks. FDPM, which considers the frequency dependence of cable and line parameters, is used to model the underground cable and overhead line section (Hoogendorp, 2016).

In this study, the capacitive effect of XLPE type cables in a 5500m lengthy distribution network is examined, and the results obtained by modeling in PSCAD / EMTDC program are compared with the measurements from the system. To eliminate the capacitive reactive effect of the XLPE cable, the contribution of the shunt reactor to the network is compared with the results obtained from the simulation program for both inactive and several active stages. Furthermore, it is ensured that the correct compensation method is examined in terms of efficiency instead of the classical compensation methods. Also, the effects of the installation at the different points on the system are examined with the obtained results.

\section{Material and Methods}

\subsection{Cross-Connected Polyethylene (XLPE) Underground Cables and Capasistive Effect}

The constructional components and structure of the cable used in this study are gathered from the catalog values of $1 \times 95 / 16 \mathrm{~mm}^{2}$ XLPE type cable ("HES Kablo", n.d.)

The cable structure and essential R-L-C values are used to calculate the relationships between the parameters in energy transmission and distribution lines and change according to the characteristics of the line, which are similar to capacitors. In underground cables, single-core cables are screened with the help of a grounded metal sheath. When energy is carried over three phases in single-core lines, since each stage is screened again using a grounded metal sheath, it is always enough to consider only the electric field between the conductor and the metal sheath.

The capacitance carries vital importance in underground cables and affects all power distribution systems while it can almost be neglected for short transports in overhead lines. 


\subsection{Reactive Power Compensation}

Medium voltage distribution networks have different compensation systems that of low voltage. Due to the high power required by these enterprises, they establish and operate power transformers within their structure. In this way, classical compensation systems on the low voltage side do not eliminate the reactive power problem. Compensation systems on the conventional low voltage side are insufficient, especially when the active consumption is moderate and the transformer is idle. The main reasons for such issues can be listed as

- inductive effect caused by the transformer cannot be adjusted according to variable currents,

- measurement and response sensitivity of compensation systems are insufficient at high powers,

- insufficient sensitivity of measurement transformers and measuring instruments are due to low currents drawn during low consumption,

- reactive power on the MV side creates an inductive and capacitive changing condition due to the phase imbalance in the idle transformers,

- and there is a distance between the power meters and transformer centers.

In an implemented project, the MV line with a distance of about $2 \mathrm{~km}$ was not considered when designing the compensation system, and compensation was designed for LV systems. When the facility was commissioned, the compensation system compensated the capacitive and inductive reactive powers in the LV systems without any problems. However, since the electricity meter of the facility was MV referenced, capacitive reactive power was generated on the line with the effect of the $2 \mathrm{~km}$ XLPE cable. As a result of the calculations made for this effect, the virtual step adjustment was made to the reactive power control relay in the LV compensation system as much as the capacitive effect of the XLPE cable, and the system was compensated temporarily. In addition, it is suggested to make compensation with $\mathrm{MV}$ referenced shunt reactor at the beginning of the line next to the compensation in LV systems.

Making the appropriate analysis can ensure that the electrical energy is used with minimum cost and maximum efficiency. With the correct load analysis, the correct compensation method and location should be determined. In addition to the compensation systems made on the LV side, MV compensations should also be made, and they should be done at the right point in terms of total efficiency. MV distribution centers, step-down substations, substations where more than one line is separated can be the right points. In terms of energy continuity and efficiency, all energy transmission and distribution system elements should be evaluated as a whole. A comparison of compensation systems can be found in Table 1 . This study was focused on the MV referenced shunt reactor compensation system to overcome XLPE effects, and the existence of the LV compensation system was assumed.

Another part of the compensation system is shunt reactors, which are also called inductive power generators. It is applied to compensate for the voltage rises and reactive (capacitive) power caused by the Ferranti effect in the lines. Ferranti effect increases the network voltage up to 1.2 times in remote stations in long lines without compensation (Shekhar et al., 2017). Shunt reactors consume the power generated by the capacitive loads. They are like transformers because of evaluated as inductive. However, shunt reactors differ from transformers in electrical properties, structures, and application forms. 
Tablo 1. Comperations of compensation systems

\begin{tabular}{lccc}
\hline & & & LV \\
\hline & $\begin{array}{c}\text { Capacitive Reactive } \\
\text { Power (kVAR) }\end{array}$ & $\begin{array}{c}\text { Inductive Power } \\
\text { (kVAR) }\end{array}$ & $\begin{array}{c}\text { Capacitive Reactive } \\
\text { Power (kVAR) }\end{array}$ \\
\hline No Compensation & Noneffective & Noneffective & Noneffective \\
\hline $\begin{array}{l}\text { Classic LV referenced } \\
\text { compensation (Pashaie et } \\
\text { al., 2011) }\end{array}$ & Noneffective & Effective & Noneffective \\
$\begin{array}{l}\text { LV referenced Shunt } \\
\text { Reactor Compensation } \\
\text { (Chen et al., 2015; Jin et } \\
\text { al., 1994) }\end{array}$ & Effective & Effective & Noneffective \\
\hline $\begin{array}{l}\text { MV referenced Shunt } \\
\text { Reactor Compensation } \\
\text { (This study) }\end{array}$ & Effective & & \\
\hline
\end{tabular}

\begin{tabular}{llll}
\hline *Combined & Effective & Effective & Effective \\
Compensation & &
\end{tabular}
* Combined Compensation Systems: Both Classical LV Referenced Shunt Reactor Compensation and MV Referenced Shunt
Reactor Compensation

\subsection{The Calculation of Cable Line Constants with PSCAD/EMTDC}

For simulation setup, data for a single-core XLPE insulated underground cable with $5.586 \mathrm{~km}$

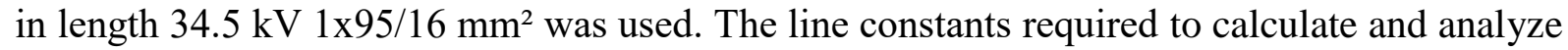
the distribution network in the PSCAD/EMTDC program were calculated. The catalog values were converted into the input data to calculate the cable line constants (Santos \& Calafat, 2019). The results obtained for the underground cable from the PSCAD/EMTDC program and the subcalculation program are compared in Table 2 . The program calculates serial-impedance, shuntadmittance matrices, resistance, inductance, and capacitance values for the pi equivalent circuit modeling using the additional setting features.

Table 2. The electrical properties of the $1 \times 95 / 16 \mathrm{~mm}^{2}$ XLPE cable.

\begin{tabular}{lll}
\hline Line Constants & Catalog Values & $\begin{array}{c}\text { Calculated } \\
\text { Values }\end{array}$ \\
\hline Resistance & $0.247 \Omega / \mathrm{km}$ & $0.247 \Omega / \mathrm{km}$ \\
Capacitance & $0.15 \mu \mathrm{F} / \mathrm{km}$ & $0.15 \mu \mathrm{F} / \mathrm{km}$ \\
Inductance & $0.60 \mathrm{mH} / \mathrm{km}$ & $0.66 \mathrm{mH} / \mathrm{km}$ \\
\hline
\end{tabular}




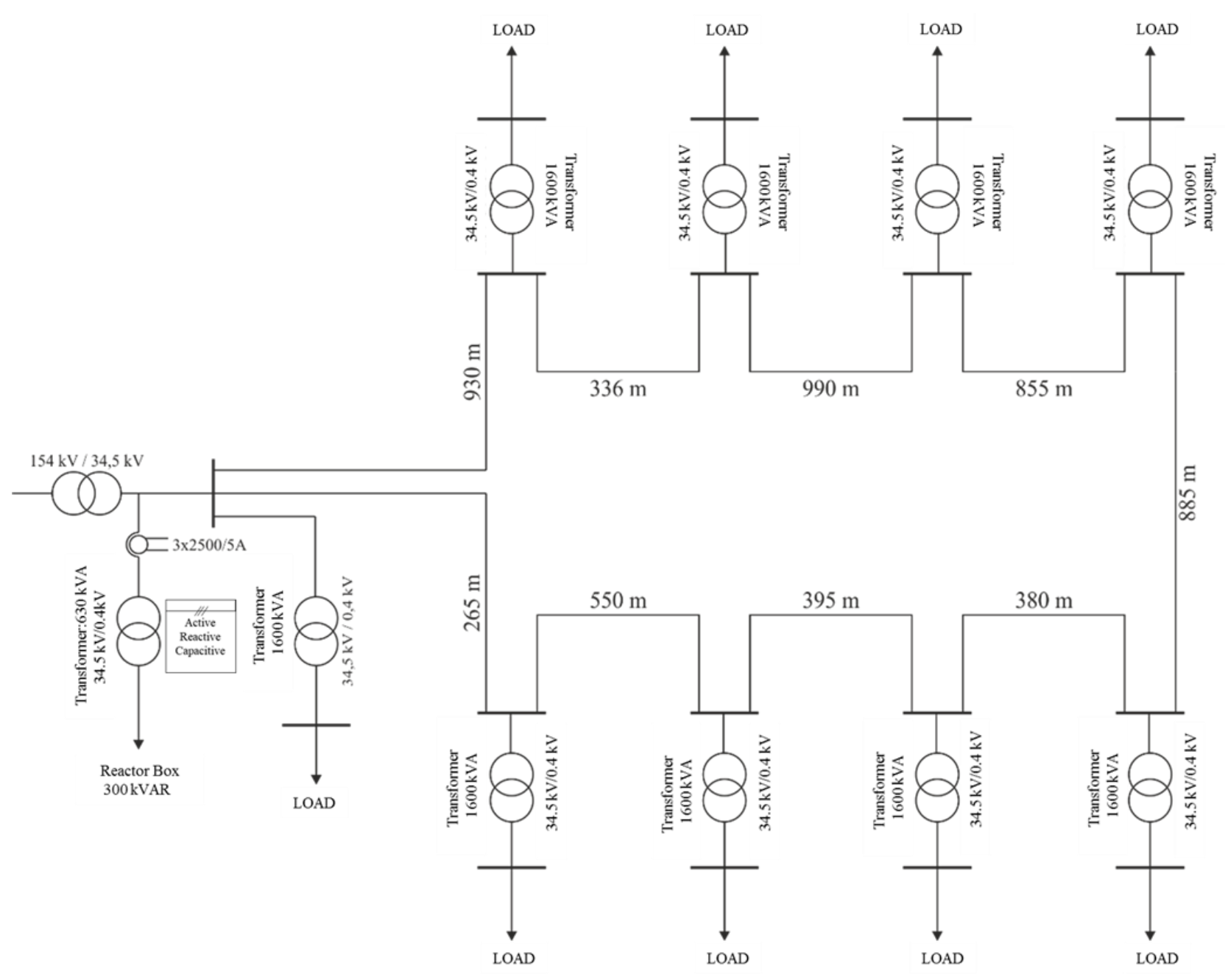

Figure 1. A single line of the ring networks

\section{Research Findings}

\subsection{Powers in MV Distribution Network Established with XLPE Cable Results}

The total power of the facility, which has an installed capacity of approximately 10 MVA, is shared by nine different transformer centers to meet its energy needs. The transformer centers are established in the form of ring networks. They can be fed from the other section of the line if any breakdown occurs at any point without power interruption. The total length of the line of $34.5 \mathrm{kV}\left(1 \times 95 / 16 \mathrm{~mm}^{2}\right)$ XLPE type cable is approximately 5586 meters. According to the catalog value for $1 \times 95 / 16 \mathrm{~mm}^{2}$ XLPE type cable, the capacitance for one km length is $\mathrm{C}=0.153$ $\mu \mathrm{F} / \mathrm{km}$. Thus, we can calculate the capacitive reactance as $2.12 \times 10^{\wedge} 4 \Omega$, the current as $0.941 \mathrm{~A}$, and the capacitive power as $6.24 \mathrm{kVAR} / \mathrm{km}$. As a result, the total capacitive power for the $5.586 \mathrm{~km}$ line is $314.5 \mathrm{kVAR}$ (see Figure 1).

A capacitive reactive power of approximately $315 \mathrm{kVAR}$ will occur due to the capacitive effect of the medium voltage cable in the time intervals when energy consumption drops. Therefore, a $300 \mathrm{kVAR}$ shunt reactor panel, given in Figure 2, has been installed to eliminate the capacitive effect caused by the XLPE type underground cable in the current distribution system. The 
reactor panel installed has 12 stages with $300 \mathrm{kVAR}$ power. Each stage is manually switched and has a power of $25 \mathrm{kVAR}$. Compensation is performed by activating the steps according to the active and reactive power values taken from the meter.

The drawn powers at certain times of a day are measured at the region fed by the distribution network. The intensity of the power drawn during working hours increased, and the need for active power decreases to lower levels during the night hours. In the intervals where the load density is high, the capacitive effect resulting from the underground cable is compensated to a certain extent using inductive loads, and the results are shown in Table 3.

In Case 1, the shunt reactor is not engaged, and the active power of three phases drawn from the distribution line is $815 \mathrm{~kW}$. However, the capacitive reactive power drawn from the network is $307 \mathrm{kVAR}$. This value, close to the calculated one, is due to the capacitive effect of the underground cable.

Table 3. The power measurement results from the analyzer in the system.

\begin{tabular}{lcccc}
\hline Case No & $\mathbf{1}$ & $\mathbf{2}$ & $\mathbf{3}$ & $\mathbf{4}$ \\
\hline $\begin{array}{l}\text { The number of } \\
\text { Active Reactors }\end{array}$ & - & 4 & 8 & 12 \\
$\begin{array}{l}\text { Active } \\
\text { Power (kW) }\end{array}$ & 815 & 741 & 632 & 783 \\
$\begin{array}{l}\text { Capacitive Reactive } \\
\text { Power (kVAR) }\end{array}$ & 307 & 205 & 98 & 6 \\
$\begin{array}{l}\text { Inductive } \\
\text { Power (kVAR) }\end{array}$ & - & 100 & 200 & 300 \\
\hline
\end{tabular}

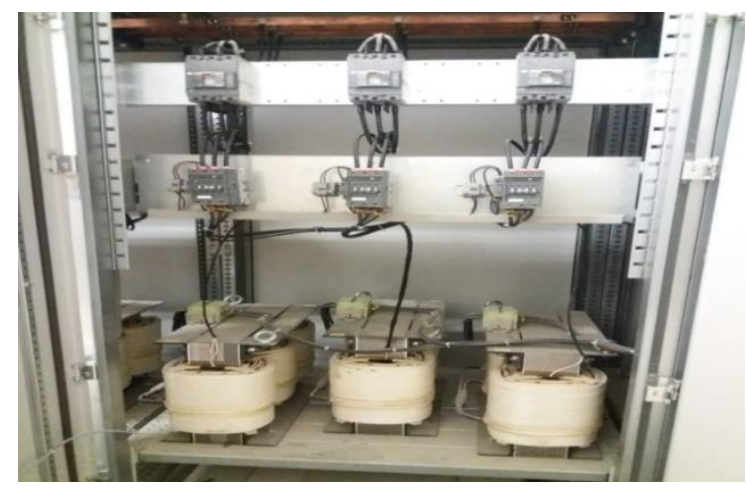

Figure 2. The shunt reactor panel.

In Case 2, four stages of the shunt reactor have been activated. An inductive power of 100 $\mathrm{kVAR}$ is supplied to the distribution network. As a result, the capacitive reactive power value is decreased to $205 \mathrm{kVAR}$. In Case 3, the number of stages in the circuit is increased to eight resulting in the active power of $632 \mathrm{~kW}$ and the capacitive reactive power of $98 \mathrm{kVAR}$ drawn from the distribution line.

Finally, in Case 4, all the shunt reactors are commissioned. The total active power of the three phases is $783 \mathrm{~kW}$, and the capacitive reactive power decreases down to $6 \mathrm{kVAR}$. The first issue to be considered here is that the active power changes in all cases are not related to the 
compensated system realized with the shunt reactor. Instead, it is due to the instantaneous active power usage in the measured moments.

\subsection{PSCAD/EMTDC Simulation Results}

The single busbar power distribution line created in the PSCAD/EMTDC program based on the distribution network data presented in Section 3.1 is shown in Figure 3. The source feds the line by a balanced three-phase system with a line voltage of $34.5 \mathrm{kV}$ and an operating frequency of $50 \mathrm{~Hz}$. The network was created in the form of a $\pi$-model that reflects the required line parameters associated with a line of 5586 meters. A single $\pi$-model instead of a serially connected model brings the advantages of smaller data size, a smaller number of nodes, a shorter calculation time, and a smaller matrix size. The total load in the distribution system, analyzed with a transformer in the load section, is shown at one point. It consists of 12 stages, each with a power of $25 \mathrm{kVAR}$, in the distribution network where shunt reactor analysis is performed.

In the simulation, to achieve time and data size efficiency, the network was reduced to three stages of $100 \mathrm{kVAR}$, each representing the four components. A separate switching element was used for switching in each stage. The connection of the shunt reactor with the distribution network is carried out with a $630 \mathrm{kVA}$ transformer connected in parallel. The simulation was carried out for 10 seconds duration in a step size of $250 \mu \mathrm{s}$.

Figure 4 shows the three-phase active-reactive power values at the source, the end of the line, and the load side. When the load is disengaged $(0-1 \mathrm{~s}$.), the value of the active power drawn from the source is approximately $7 \mathrm{~kW}$. The reactive effect of the XLPE type underground cable without activating the shunt reactor and load causes the reactive charging currents to flow over the line. The capacitive reactive power is generated due to the currents in question. Its direction contrasts with active power and towards the source since it supplies the power to the network. So, it is seen on the negative axis. The measured value of this power is approximately $-318 \mathrm{kVAR}$. The active power value is measured as $818 \mathrm{~kW}$ with the load activation $(1-10 \mathrm{~s})$, and the reactive power is $-277 \mathrm{kVAR}$. The difference is due to the inductive and capacitive power exchange between the load and the line. It is important to note that the transformer windings in front of the load are inductive and affect the reactive power. 


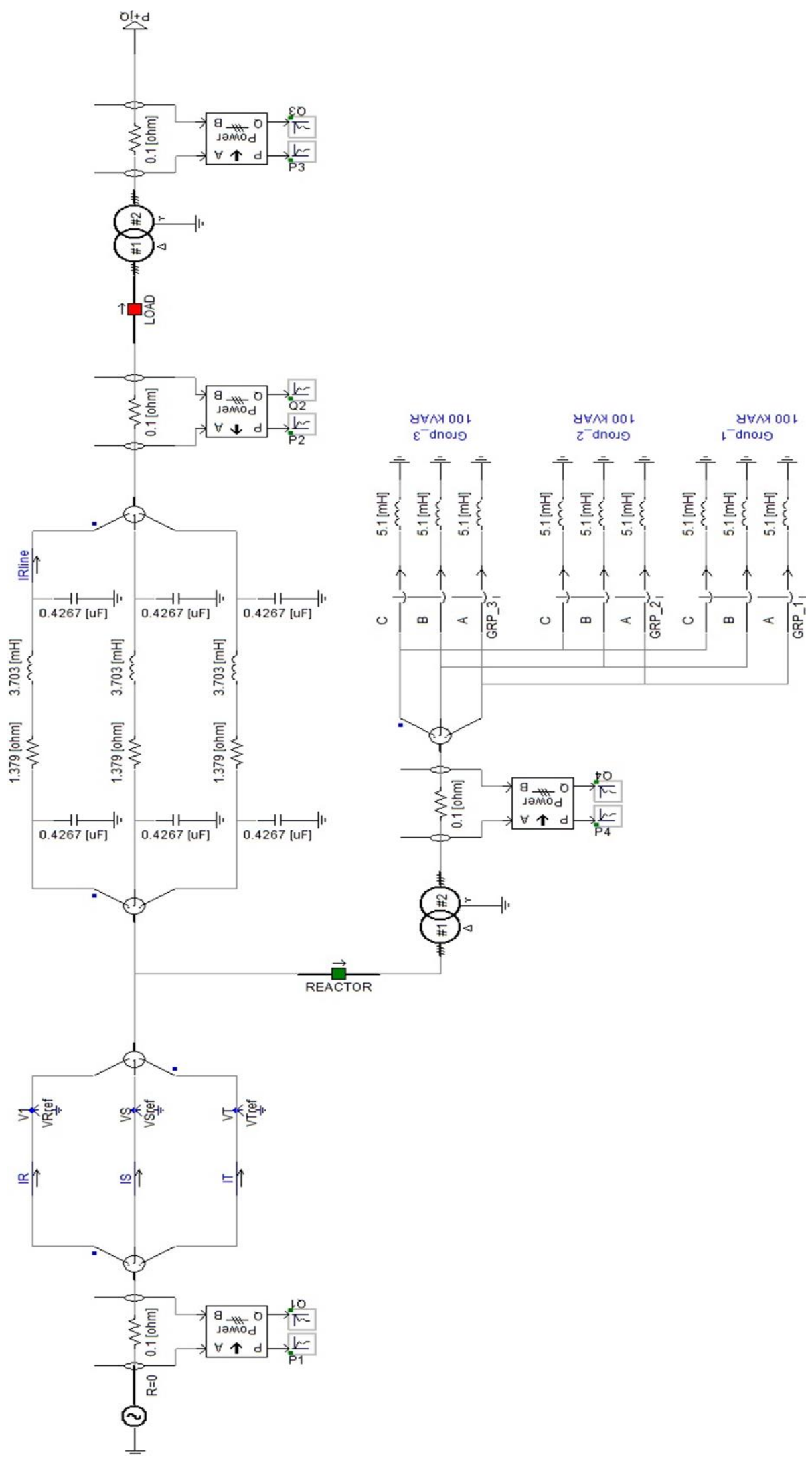

Figure 3. The simulation of XLPE underground cable at the PSCAD program. 


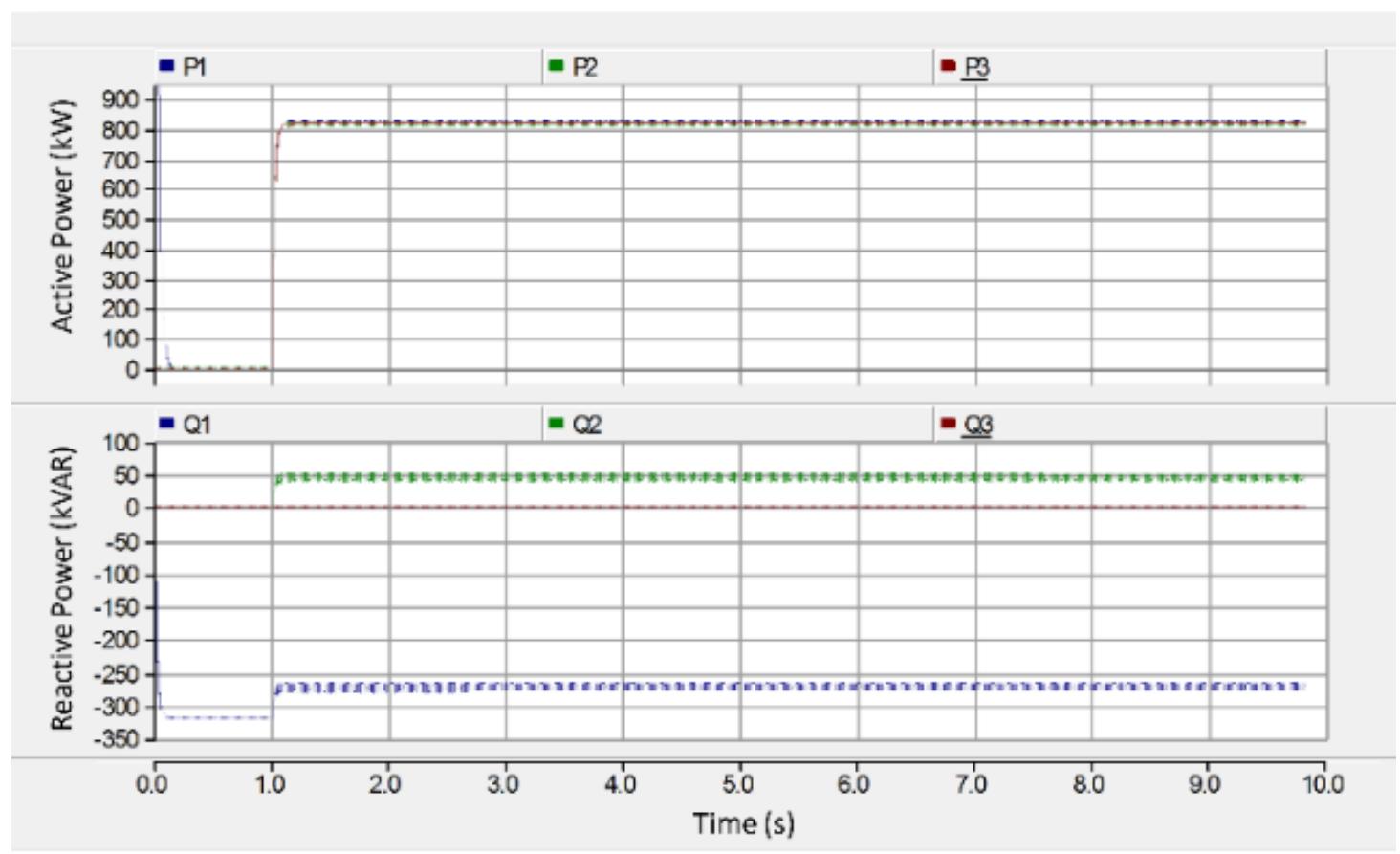

Figure 4. The total active and reactive powers of three phases; at the source side (P1 and Q1), the end of the line (P2 and Q2), and the load side (P3 and Q3), the load and the shunt reactors are not connected.

The active and reactive power (P2-Q2) examination at the end of the line shows that the active power value is $1.18 \mathrm{~kW}$ when the load is not connected (0-1 s). In this time duration, the reactive power is $9.8 \mathrm{kVAR}$ at the end of the line, while it was measured as $-318 \mathrm{kVAR}$ at the source side. The change in reactive power is due to the lack of capacitive effect of the XLPE cable at the line. The active power value (P2) measured with connected load is $817 \mathrm{~kW}$ which is approximately the same as the active power value per line, and the reactive power is $45 \mathrm{kVAR}$. Figure 4 also shows that active and reactive power at the load rises to $817 \mathrm{~kW}$ and approximately $1 \mathrm{kVAR}$, respectively, through the connection of the load. Since the measuring point is in the LV part, the inductive reactive power value originating from the transformer is not read. 


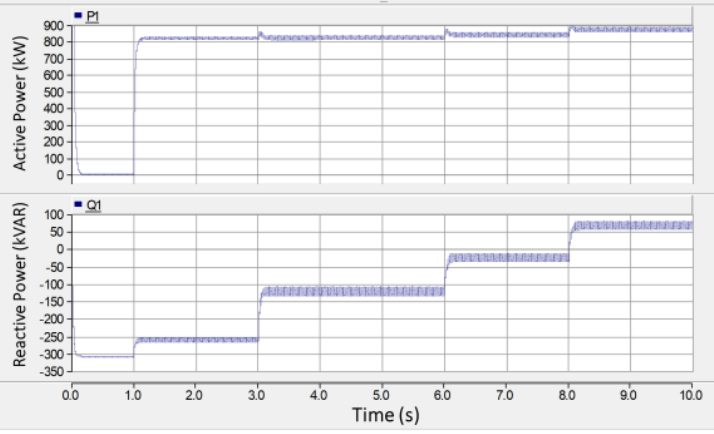

(a)

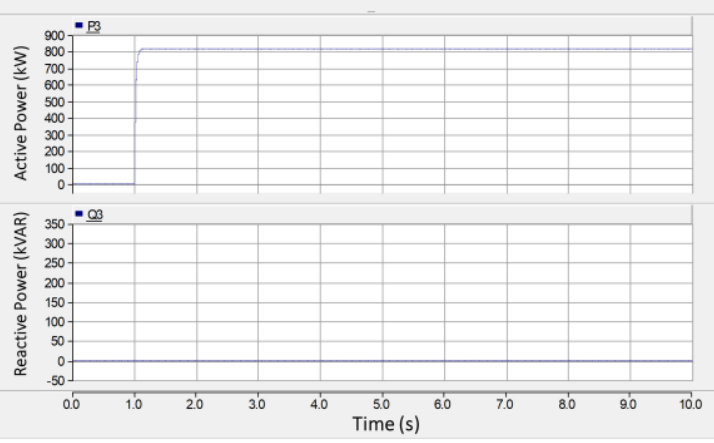

(c)

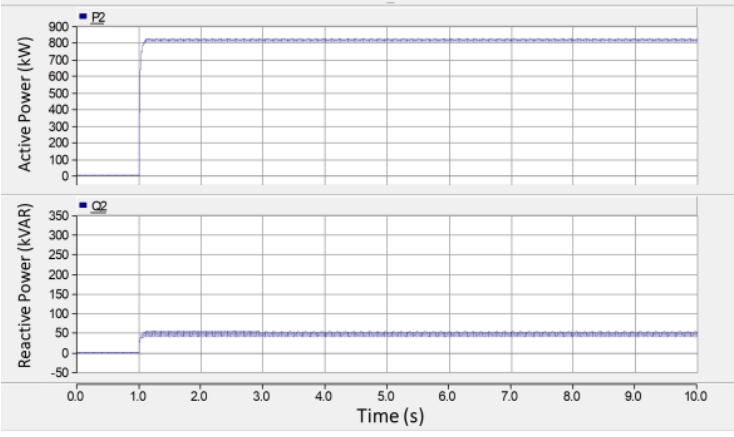

(b)

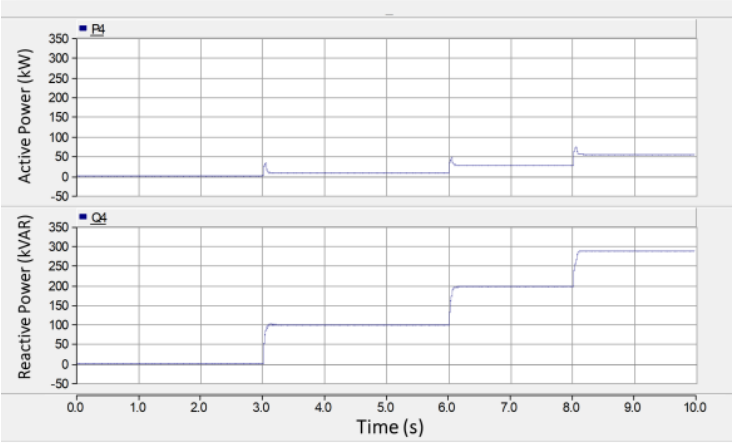

(d)

Figure 5. The simulation results of the total active and reactive powers for the three phases (a) at the source side, (b) the end of the line, (c) the load side, and (d) the shunt reactor side when the shunt reactor is connected.

Figure 5 summarizes the power simulation results when the shunt reactor is in operation, clearly shows that both active and reactive powers experience significant changes. Here, the shunt reactor stages are commissioned at different time intervals.

At the source side, as seen in Figure 5.a, the active power value is approximate $818 \mathrm{~kW}$ with the commissioning of the load (1-3 s), and the reactive power value decreases to $-259 \mathrm{kVAR}$. The difference is due to the inductive and capacitive power exchange between the load and the line. Active power value is determined as $820 \mathrm{KW}$ with the first stage of shunt reactor (100 kVAR) during 3-4 s. The active power value shown in the graph remains approximately constant, although small power fluctuations occur when the reactor is activated. The reactive power value (3-4 s) is -121 kVAR. The coil windings of transformers cause the difference of $138 \mathrm{kVAR}$ in front of the shunt reactor and the first stage of the shunt reactor with $100 \mathrm{kVAR}$. In the range of $6-8 \mathrm{~s}$, the second stage of the shunt reactor with a power of $100 \mathrm{kVAR}$ is activated. The active power value is $843 \mathrm{KW}$, and the reactive power value decreases to -36 $\mathrm{kVAR}$. With the introduction of the last stage of the shunt reactor in the range of 8-10 s, the reactive power value increases to $+78 \mathrm{kVAR}$, and the active power value is $875 \mathrm{~kW}$.

At the end of the line, the active power value is determined as $817 \mathrm{~kW}$, and the reactive power value is $45 \mathrm{kVAR}$ via connection of the load, as seen in Figure 5.b. Thus, there is no change in both the active and the reactive power values in the time intervals when the shunt reactor steps are activated. 
At the load side, the active power value is $817 \mathrm{KW}$, and the reactive power value is $2 \mathrm{kVAR}$, as seen in Figure 5.c. Thus, the operation of the shunt reactor does not cause any change on the load side, and both the active and the reactive power values remain constant.

At the shunt reactor side, the active power values are $6 \mathrm{KW}$ in the first, $25 \mathrm{~kW}$ in the second, and $54 \mathrm{~kW}$ in the third stage, as seen in Figure 5.d. The reactive power values are $99 \mathrm{kVAR}$ in the first, $195 \mathrm{kVAR}$ in the second, and $287 \mathrm{kVAR}$ in the third stages.

Figure 6 shows the RMS values of the change in phase currents drawn from the source. During $0-1 \mathrm{~s}$, the current of 5.16A is drawn from the source when the load is not connected. This current value rises due to the line constants of the XLPE type underground cable and causes the line to be loaded unnecessarily when the load at the end of the line is not active. The current value is drawn from the network between 1-3 s increases with the activation of the load, and the active power value drawn from the network increases. So, the current value drawn from the network raises to $14.40 \mathrm{~A}$.

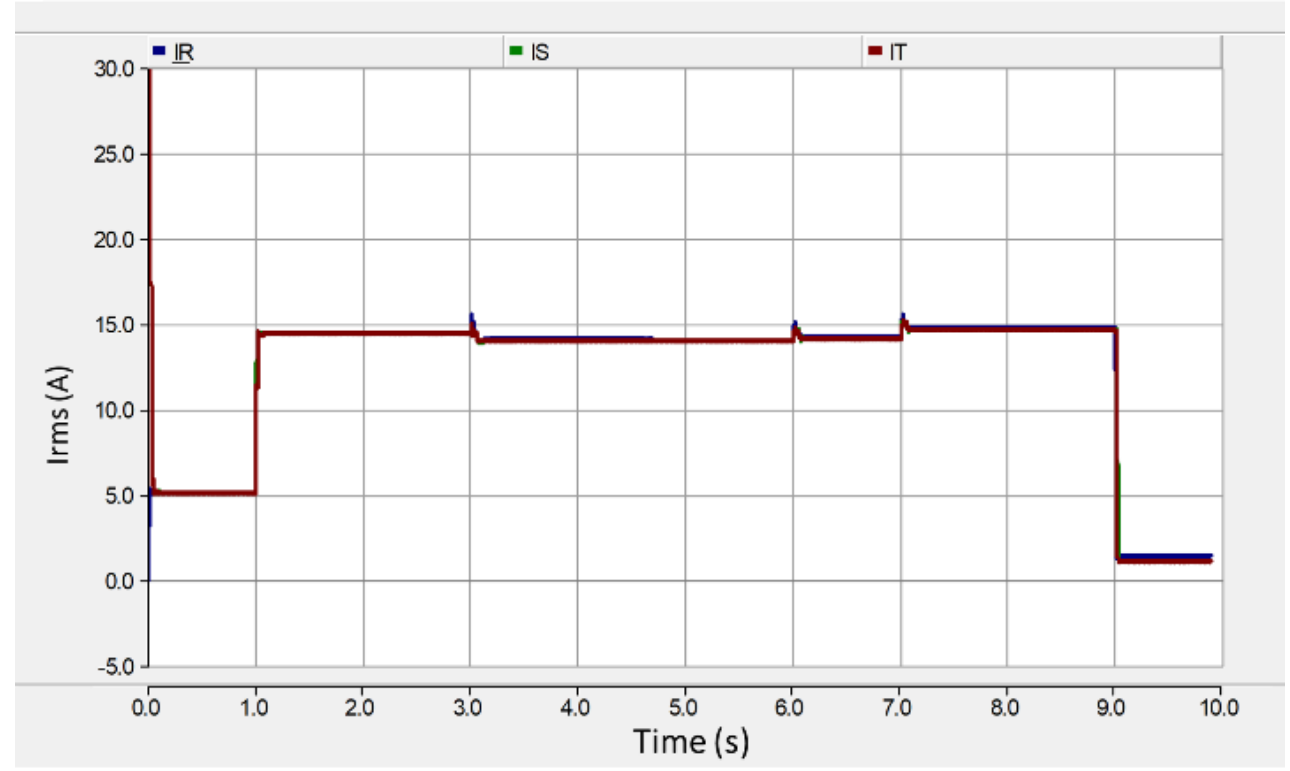

Figure 6. RMS changes in the phase currents drawn from the source.

The shunt reactor stages have been fully activated between $3-6 \mathrm{~s}$, as seen in Figure 6 . At the end of $6 \mathrm{~s}$, it has reached a stable operation, and the balanced phase currents are settled to an RMS value of $14.70 \mathrm{~A}$. After $9 \mathrm{~s}$, the load is deactivated, but the reactive current caused by the capacitive effect of the underground cable between 0-1 s is also compensated. As a result, the current drawn from sources is only $1 \mathrm{~A}$ due to the serial impedance of the underground cable.

The changes in the current and voltage of the $\mathrm{S}$ phase drawn from the source in different time intervals are given in Figure 7. Due to the capacitive effect of XLPE type cable, there is approximately $86.4^{\circ}$ phase difference between the current and the voltage, and the current is ahead. However, when the load and shunt reactors are active, the phase difference between current and voltage has regressed to $3^{\circ}$, indicating that inductive-capacitive current exchange eliminates the phase difference between the current and the voltage by the activation of the shunt reactor. 

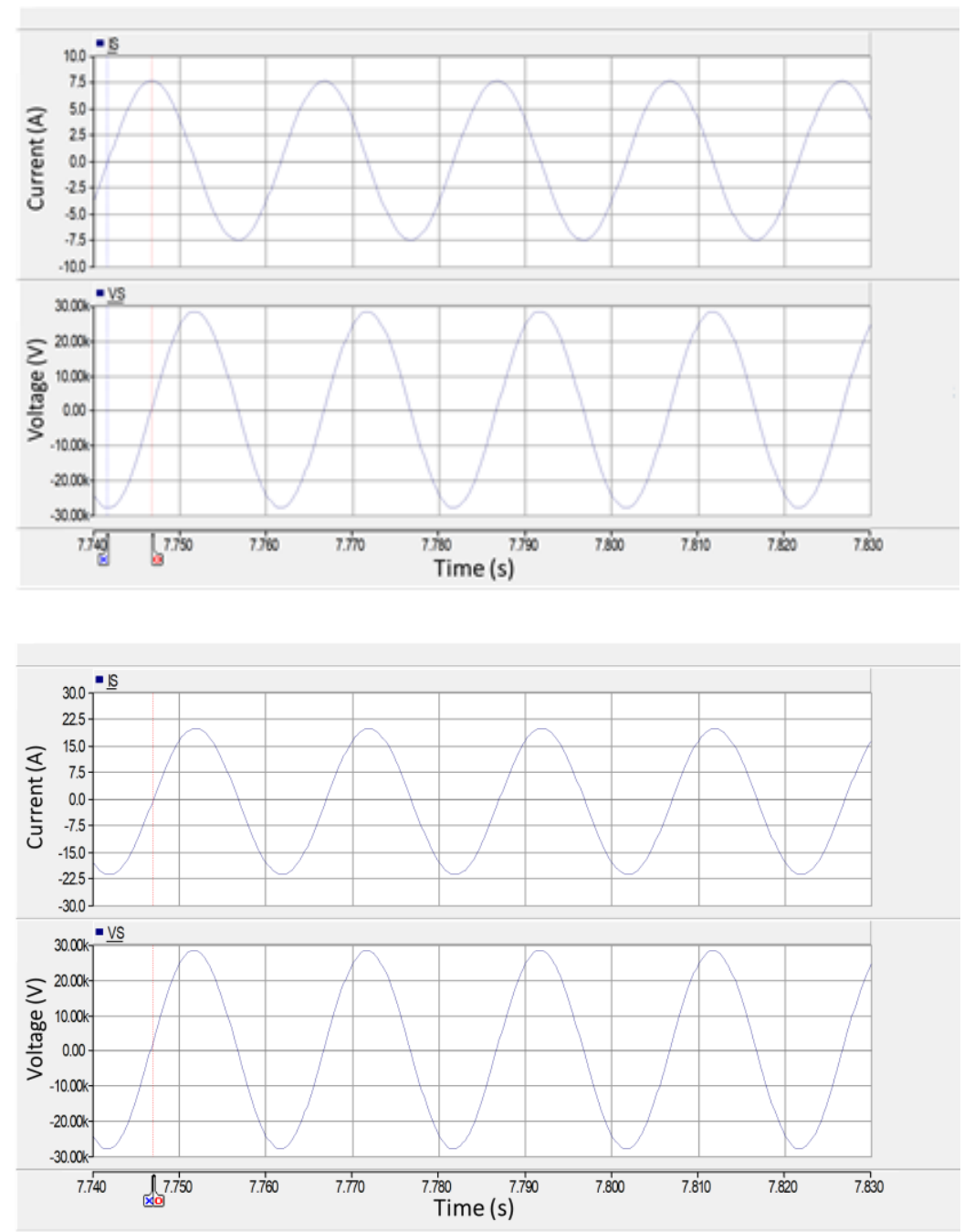

Figure 7. S-phase current and voltage drawn from the source when the load and the shunt reactor are not in operation (above) and in operation (below).

\section{Conclusions}

XLPE cables, due to their constructional properties, cause considerable capacitive reactive power in the MV networks and imposes undesired load that must be eliminated. To explore this undesired effect, simulate the characteristics of the capacitive reactive power, and eliminate it through shunt reactors, a simulation study is performed by modeling XLPE cable using data of distribution network analyzed and PSCAD / EMTDC program. The measurements and simulation results were found to be highly consistent.

The network was examined during the hours when the energy consumption is deficient where approximately an average power consumption of $800 \mathrm{~kW}$ and capacitive reactive power of 300 $\mathrm{kVAR}$ that is approximately $37.5 \%$ of the active power which is near twice the $15 \%$ value allowed by the Turkish Electricity Distribution Corporation (TEDAS) and the other energy distribution companies.

In the simulation study, active and reactive power fluctuations are observed during the commissioning of the load and shunt reactor stages. Serial resistance of XLPE type underground cables is lower than overhead lines. It is observed that the reactive current 
components drawn over the line are reduced by compensation with the shunt reactor while the line is idle. As a result, the current components reduce the voltage drops created by the series impedance of the line, and the end-of-line voltage regulation is not excessive. The compensation via shunt reactors also decreases the phase shifts and reduces to $3^{\circ}$ level.

As a result, using the correct analysis, electrical energy with minimum cost and maximum efficiency can be provided. The correct compensation method and location should be determined by performing the load analysis correctly. All energy transmission and distribution system elements should be evaluated in terms of energy continuity and efficiency.

\section{Acknowledgment}

This paper is based on the Master Thesis written by Salih Bilgic under the supervision of Dr. Cemile Bardak (Bilgiç, 2020). We thank Prof.Dr. Nevzat Onat for his valuable comments during the research progress.

\section{References}

Ahmad, T., \& Zhang, D. (2020). A critical review of comparative global historical energy consumption and future demand: The story told so far. Energy Reports, 6, 1973-1991. https://doi.org/https://doi.org/10.1016/j.egyr.2020.07.020

Bilgiç, S. (2020). Investigation of Capacitive Effect on XLPE Type Medium Voltage Cables. Graduate School of Applied and Natural Sciences, Manisa Celal Bayar University, 103.

Chen, S. X., Eddy, Y. S. F., Gooi, H. B., Wang, M. Q., \& Lu, S. F. (2015). A centralized reactive power compensation system for LV distribution networks. IEEE Transactions on Power Systems, 30(1), 274-284. https://doi.org/10.1109/TPWRS.2014.2326520

HES Kablo. (1390). HES Kablo Enerji Katalog. Retrieved June 7, 2021, from https://www.hes.com.tr/assets/doc/Enerji_Katalog.pdf

Hoogendorp, G. (2016). Steady State and transient behavior of underground cables in $380 \mathrm{kV}$ transmission grids. https://doi.org/10.4233/uuid:2ecf0e07-58c8-42b9-bbf1-67878a3f6018

Janning, J., \& Bocquel, A. (2005). Multi-level medium voltage inverters for reactive power and harmonic compensation. In 2005 European Conference on Power Electronics and Applications (Vol. 2005). IEEE Computer Society. https://doi.org/10.1109/epe.2005.219468

Jin, H., Member, G. G., Lopes, L., \& Member, S. (1994). An Efficient Switched-Reactor-Based Static Var Compensator. IEEE Transactions on Industry Applications, 30(4), 998-1005. https://doi.org/10.1109/28.297917

Liu, Y., Zhang, S., Cao, X., Zhang, C., \& Li, W. (2018). Simulation of electric field distribution in the XLPE insulation of a $320 \mathrm{kV}$ DC cable under steady and time-varying states. IEEE Transactions on Dielectrics and Electrical Insulation, 25(3), 954-964. https://doi.org/10.1109/TDEI.2018.006973

Malik, N. H., Pazheri, F. R., Al-Arainy, A. A., \& Qureshi, M. I. (2014). Analytical Calculation of AC and DC Electric Field Distribution at High Voltage Cable Terminations. Arabian Journal for Science and Engineering, 39(4), 3051-3059. https://doi.org/10.1007/s13369-013-0939-9 
Pashaie, A., Zahawi, B., \& Giaouris, D. (2011). Distributed Static Series Compensation for distribution network line voltage profile improvement. IEEE PES Innovative Smart Grid Technologies Conference Europe, 13-16. https://doi.org/10.1109/ISGTEurope.2011.6162823

Popović, L. M. (2020). Inductive influence of surrounding metal installations on power transfer capacity of HV cable lines with applied cross-bonding. International Journal of Electrical Power and Energy Systems, 120. https://doi.org/10.1016/j.ijepes.2020.105963

Ra, N., Mustafa, N. S. B., Kawashima, T., Murakami, Y., \& Hozumi, N. (2019). Development of a Partial Discharge Measuring Method for a Long-Distance Cable Line. IEEJ Transactions on Electrical and Electronic Engineering, 14(7), 996-1001. https://doi.org/10.1002/tee.22894

Santos, M., \& Calafat, M. A. (2019). Dynamic simulation of induced voltages in high voltage cable sheaths: Steady state approach. International Journal of Electrical Power and Energy Systems, 105, 1-16. https://doi.org/10.1016/j.ijepes.2018.08.003

Schönleber, K., Collados, C., Pinto, R. T., Ratés-Palau, S., \& Gomis-Bellmunt, O. (2017). Optimization-based reactive power control in HVDC-connected wind power plants. Renewable Energy, 109, 500-509. https://doi.org/10.1016/j.renene.2017.02.081

Shekhar, A., Kontos, E., Ramírez-Elizondo, L., Rodrigo-Mor, A., \& Bauer, P. (2017). Grid capacity and efficiency enhancement by operating medium voltage AC cables as DC links with modular multilevel converters. International Journal of Electrical Power and Energy Systems, 93, 479-493. https://doi.org/10.1016/j.ijepes.2017.06.012

Thomas, H., Marian, A., Chervyakov, A., Stückrad, S., Salmieri, D., \& Rubbia, C. (2016). Superconducting transmission lines - Sustainable electric energy transfer with higher public acceptance? Renewable and Sustainable Energy Reviews, 55, 59-72. https://doi.org/10.1016/j.rser.2015.10.041

Türkiye Elektrik İletim Anonim Şirketi. (n.d.). Retrieved June 7, 2021, from https://www.teias.gov.tr/

Werelius, P., Thärning, P., Eriksson, R., Holmgren, B., \& Gäfvert, U. (2001). Dielectric spectroscopy for diagnosis of water tree deterioration in XLPE cables. IEEE Transactions on Dielectrics and Electrical Insulation, 8(1), 27-42. https://doi.org/10.1109/94.910423

Werelius, Peter, Holmgren, B., \& Gafvert, U. (1998). Diagnosis of medium voltage XLPE cables by high voltage dielectric spectroscopy. In IEEE International Conference on Conduction \& Breakdown in Solid Dielectrics (pp. 79-84). https://doi.org/10.1109/icsd.1998.709231

Yu, Q., Li, X., Zhang, P., Yang, P., \& Chen, Y. (2019). Properties of Water Tree Growing in XLPE and composites. In ICEMPE 2019 - 2nd International Conference on Electrical Materials and Power Equipment, Proceedings (pp. 409-412). Institute of Electrical and Electronics Engineers Inc. https://doi.org/10.1109/ICEMPE.2019.8727376

Zhang, Y., Chen, C., \& Liao, M. (2008). Study on Lv and Mv integrated reactive power optimization in distribution networks. In 2008 China International Conference on Electricity Distribution, CICED 2008. https://doi.org/10.1109/CICED.2008.5211753 